Article

\title{
Biocompatible Fe-Based Micropore Metal-Organic Frameworks as Sustained-Release Anticancer Drug Carriers
}

\author{
Xin Leng ${ }^{1}$, Xiaoxv Dong ${ }^{2}$, Wenping Wang ${ }^{1}$, Na Sai ${ }^{1,3}$, Chunjing Yang ${ }^{1}$, Longtai You ${ }^{1}{ }^{\circledR}$, \\ Hongliang Huang ${ }^{4,5, *}$, Xingbin Yin ${ }^{1,2, *}$ and Jian $\mathrm{Ni}^{1,2, *}$ \\ 1 School of Chinese Material Medical, Beijing University of Chinese Medicine, Beijing 102488, China; \\ 20160931927@bucm.edu.cn (X.L.); wangwenp6@163.com (W.W.); yxsaina@126.com (N.S.); \\ ylt_svip@163.com (L.Y.); 20160941191@bucm.edu.cn (C.Y.) \\ 2 Beijing Research Institute of Chinese Medicine, Beijing University of Chinese \\ Medicine, Beijing 100029, China; dxiaoxv@163.com \\ 3 School of Pharmacy, Inner Mongolia Medical University, Hohhot 010110, China \\ 4 National Center for International Joint Research on Membrane Science and Technology, Tianjin Polytechnic \\ University, Tianjin 300387, China \\ 5 State Key Laboratory of Separation Membranes and Membrane Processes, Tianjin Polytechnic University, \\ Tianjin 300387, China \\ * Correspondence: huanghl@mail.buct.edu.cn (H.H.); yxbtcm@163.com (X.Y.); njtcm@263.net (J.N.); \\ Tel.: +86-138-1147-5114 (H.H.); +86-10-8473-8616 (X.Y.); +86-10-8428-6407 (J.N.)
}

Received: 2 September 2018; Accepted: 26 September 2018; Published: 28 September 2018

\begin{abstract}
Sustained-release preparation is a hot spot in antitumor drug research, where the first task is to select suitable drug carriers. Research has revealed that carboxylic acid iron metal-organic frameworks (MOFs), constructed from iron (Fe) ions and terephthalic acid, are nontoxic and biocompatible. Due to the breathing effect, the skeleton of this mesoporous material is flexible and can reversibly adapt its pore size through drug adsorption. Therefore, we chose one kind of Fe-MOF, MIL-53(Fe), as a carrier for the anticancer drug oridonin (Ori). In this work, we report the design and synthesis of MIL-53(Fe) and explore its ability as a transport vehicle to deliver Ori. MIL-53(Fe) is characterized by scanning electron microscopy and X-ray powder diffraction. A loading capacity of $56.25 \mathrm{wt} \%$ was measured by high performance liquid chromatography. This carrier was safe and nontoxic (cell viability $>95.27 \%$ ), depending on the results of 3-(4,5-dimethylthiazol-2-yl)2,5-diphenyltetrazolium bromide assays, lactate dehydrogenase assays, and Annexin V-fluoresce isothiocyanate/propidium iodide double-staining assays. After loading the drug, the structure of the MIL-53(Fe) was not destroyed, and Ori was amorphous in MIL-53(Fe). Based on an analysis of the Ori release profile, results suggest that it lasts for more than seven days in vitro. The cumulative release rate of Ori at the seventh day was about $82.23 \%$ and $91.75 \%$ in phosphate buffer saline solution at $37^{\circ} \mathrm{C}$ under $\mathrm{pH} 7.2$ and $\mathrm{pH} 5.5$, respectively. HepG2 cells were chosen to study the cytotoxicity of Ori@MIL-53(Fe), and the results show that the anticancer ratio of Ori@MIL-53(Fe) system reaches $90.62 \%$. Thus, MIL-53 can be used as a carrier for anticancer drugs and Ori@MIL-53(Fe) is a promising sustained-release drug delivery system for the cancer therapy.
\end{abstract}

Keywords: MIL-53(Fe), oridonin; sustained-release; antitumor

\section{Introduction}

Malignant tumors are a kind of disease that seriously threaten the length and quality of human life. The second highest mortality rate in humans among all kinds of diseases is due to malignant tumors. Liver cancer is the third most common cancer [1]. The treatment of liver cancer primarily 
involves high doses of chemotherapy and surgical treatment. New chemotherapeutic drugs and drug delivery systems (DDS) are urgently needed to enhance the curative effect or to reduce the side effects of cancer treatment.

Oridonin (Ori) is an ent-kaurene diterpenoid compound (Figure 1a), extracted from the medicinal herb Rabdosia rubescenes [2]. Past studies found that oridonin has conspicuous anti-tumor activity in many types of human cancer, such as triple-negative breast cancer cells [3,4], osteosarcoma cells [5], human hepatoma cells [6], prostate cancer cells [7], and myeloma cells [8]. Therefore, it has attracted wide attention. A study of the mechanism of Ori's anti-hepatocellular activity showed that it reduces G2/M arrest and apoptosis in human liver tumor cells [9] and induces HepG2 cell apoptosis by oxidative stress pathways. Prdx2, Hsp70-1, and are involved in the anticancer activity of Ori [10]. Despite the strong anticancer activity of Ori, its poor solubility in water or common oil, moderate hydrophobicity, chemical instability, and short biological half-life, all limit its clinical use. Moreover, when it is dissolved, the light and heat may lead to active group ( $\alpha$-methylene-cyclopentanone) destruction, further limiting its practical applicability [11,12]. Therefore, finding a new drug carrier to increase the stability of oridonin and improve its in vivo efficiency is important for expanding its clinical anti-tumor applications.
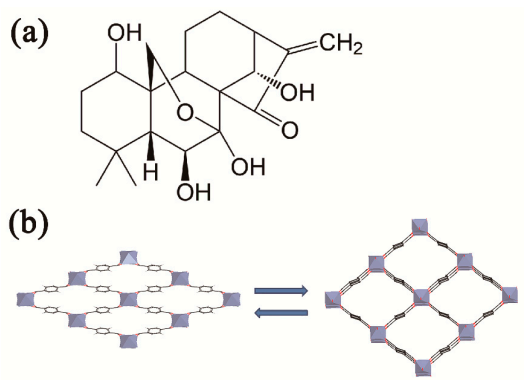

Figure 1. Structural Diagram. (a) chemical Structure of Ori and (b) respiratory effect on the mutual conversion of large and small pore of MIL-53(Fe).

Two kinds of drug delivery systems have been widely recognized: organic systems, including polymers [13,14], liposomes [15], micelles [16,17], and protein nanoparticles [11]; and inorganic systems, such as mesoporous silica nanoparticles [18-20], graphene [21], and zeolites [22]. Although organic carriers are biocompatible, the disadvantages of low loading and instability are difficult to overcome [23]. Inorganic carriers have well-defined porosity, stability, high drug loading, and enable controlled drug release, but they are hard to degrade and be removed from body [24]. Based on the above research, metal-organic frameworks (MOFs) are being widely used as drug carriers due to their unique characteristics, for example, high porosity, large specific surface area, surface paintable, pore size tunable, structural stability, non-toxicity, and biocompatibility [25-28], The Materials of Institut Lavoisiser (MIL) series is a famous type of MOF, characterized by the extremely flexible skeleton of the material, and the material structure changes between having a big hole and a narrow hole when stimulated. MIL-53(Fe) is an iron (III) carboxylate MOF [29,30]. Parallel trans corner-sharing iron (III) octahedral chains, each of which are cross-linked by 1,4-benzendicarboxylate (BDC) anions, form a one-dimensional lozenge-shaped pore channel system, which constitute the structure of MIL-53(Fe) [31]. MIL-53(Fe) can open its pores in the presence of guest drugs; hence, the skeleton of this microporous material flexibly adsorbs drugs, as shown in Figure $1 \mathrm{~b}$. The characteristic of MIL-53(Fe) is called "breathing" [32,33]. In this work, we used MIL-53(Fe) to absorb the Ori using the solvent diffusion technique. The corresponding drug-loaded MIL-53(Fe) is named Ori@MIL-53(Fe). The calculated Ori-loading capacity reached up to $56.25 \mathrm{wt} \%$ through optimizing the best loading process. The Ori@MIL-53(Fe) was evaluated for release profiles at $37^{\circ} \mathrm{C}$ in $\mathrm{pH} 5.5$ and $\mathrm{pH} 7.2$ phosphate buffer saline (PBS) solution. Ori was more slowly released, which further improved the anti-liver cancer activity. In addition, in vitro tests showed that MIL-53(Fe) had a good chemical stability with non-cytotoxicity. 


\section{Results}

\subsection{Preparation and Characteristion of MIL-53(Fe)}

MIL-53(Fe) can adapt its porosity and optimize drug-matrix interactions given its flexible framework, which allows it to maximize combination interactions and minimizing steric hindrance [31]. The method of synthesizing MIL-53(Fe) is simple and inexpensive. Furthermore, MIL-53(Fe) is chemically stable and has low toxicity, and the trace amount of dissociative iron ions can benefit for the human body.30 The prepared MIL-53(Fe) was rhombohedral, as shown in the scanning electron microscopy (SEM) images, which indicated that MIL-53(Fe) had a diameter of approximately of 2.5-3.0 $\mu \mathrm{m}$ (Figure 2a).

(a)

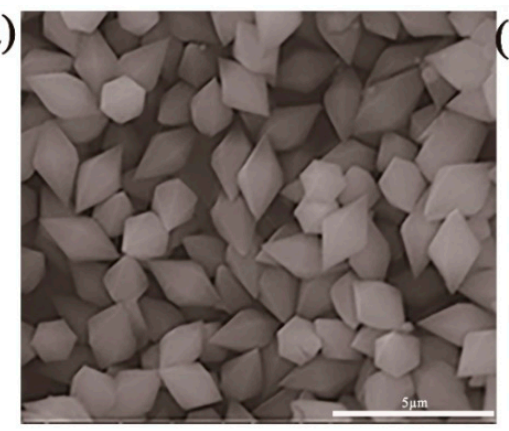

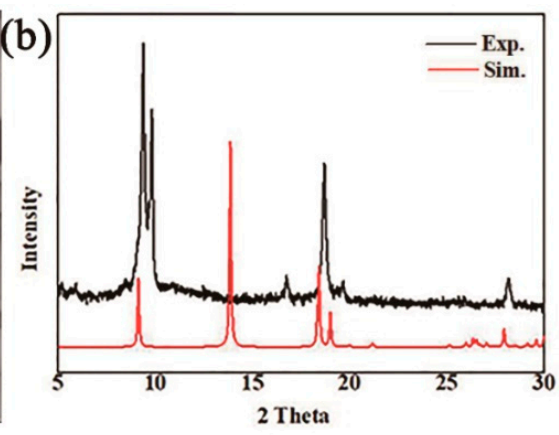

Figure 2. Characteristics of MIL-53(Fe). (a) SEM image of MIL-53(Fe), which is octahedral in diamond-shape, owing to corner-sharing chains of iron ion clusters connected through terephthalate linkers, and channels size about 2-3 $\mu \mathrm{m}$. (b) XPRD spectra of MIL-53(Fe).

X-ray powder diffraction (X-PRD) analysis was performed to analyze the powder purity of MIL-53(Fe) at room temperature (Figure 2b), and the main crystalline peaks were obvious at $9.12^{\circ}$, $18.05^{\circ}, 19.25^{\circ}$, and $28.14^{\circ}$, which agreed well with the simulated peak pattern. The Zeta potential of nanoparticle surface severely influences the dispersion stability of nanoparticles. Therefore, the Zeta potential also reflects the stability of the dispersion system. Figure 3 shows the change curve of the Zeta potential with time when MIL-53(Fe) was dispersed in fetal bovine serum (FBS). MIL-53(Fe) has good dispersion and stability serum media at $37^{\circ} \mathrm{C}$ within $48 \mathrm{~h}$.

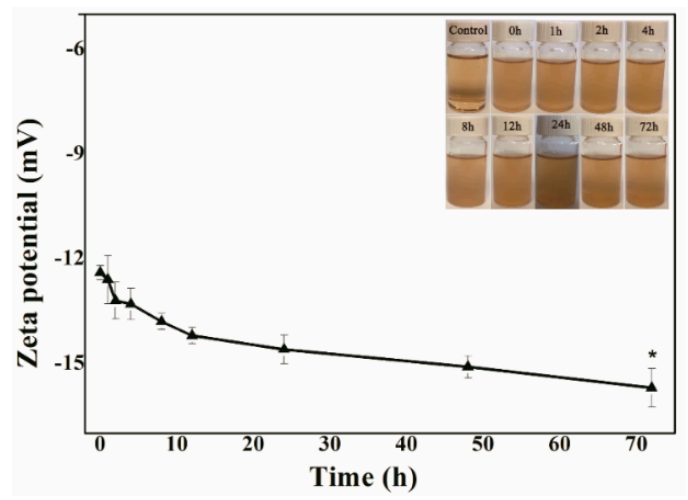

Figure 3. Zeta potential curves with time of MIL-53(Fe) in media serum at $37^{\circ} \mathrm{C}$.

\subsection{Optimal Loading Process and Characterization of Ori@MIL-53(Fe)}

By using the $\mathrm{L}_{9}\left(3^{4}\right)$ orthogonal table, three factors: proportion of Ori and MIL-53(Fe) (A), mixing time (B), and the amount of solvent (C), were selected to be optimized. No significant difference was found in the three factors $(p>0.05)$. The drug-loading rate reached up to $56.25 \mathrm{wt} \%$ under optimized conditions: MIL-53(Fe): Ori (1:4), magnetic stirring for 4 days, and MIL-53(Fe): methanol (1:0.5). The size and characteristics of the Ori@MIL-53(Fe) are shown in Figure 4. 
Through the SEM (Figure 4a) and transmission electron microscope (TEM, Figure 4b) images of Ori@MIL-53(Fe), the MIL-53(Fe) was shown to maintain its complete structure, and drugs accessed its hole or absorbed on its surface. The Fourier transform infrared (FTIR) spectra are shown in Figure 3c. The spectra of Ori@MIL-53(Fe) was consistent with the spectra of MIL-53(Fe). The intensity of the absorption peak and the small changes in the position indicate some interaction between MIL-53(Fe) and Ori. The X-ray diffraction (XRD) pattern is shown in Figure $4 \mathrm{~d}$. The absorption peak of Ori@MIL-53(Fe) completely disappeared after taking the drug, indicating that Ori was distributed in MIL-53(Fe) in the amorphous state. Differential scanning calorimetry (DSC) spectra are shown in Figure 4e, and thermogravimetric analysis (TGA) is shown in Figure 4f. The absorption thermal peak of Ori@MIL-53(Fe) significantly changed compared with Ori, showing that the crystallinity of the drug was completely lost in MIL-53(Fe).
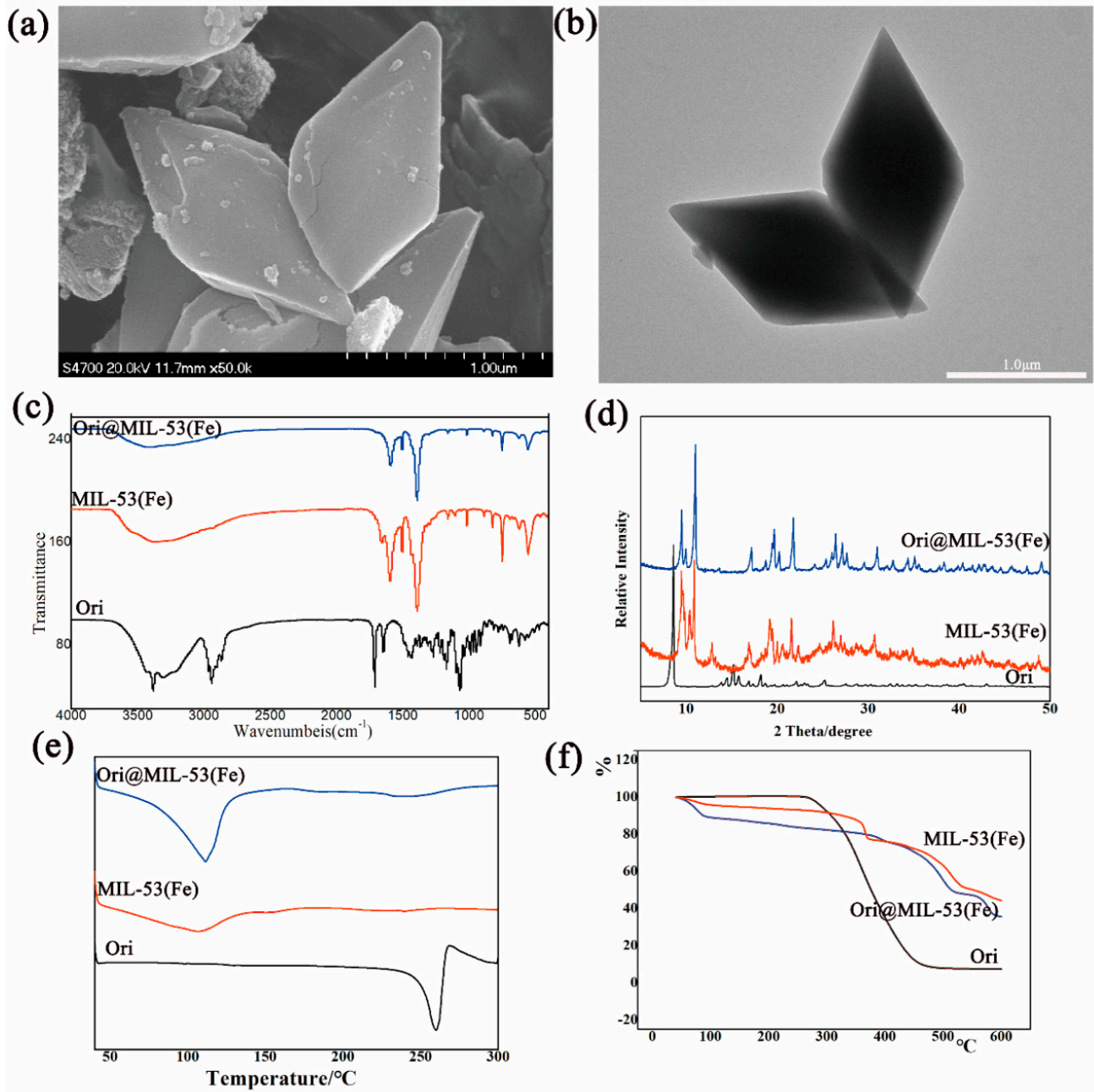

Figure 4. Characteristic of Ori@MIL-53(Fe): (a) SEM, (b) TEM, (c) FTIR, (d) XPRD, (e) DSC and (f) TGA.

\subsection{In Vitro Release Studies}

The Ori release profiles of Ori@MIL-53(Fe) was explored at two different pH values: 7.2 and 5.5. As shown in Figure 5a, the MIL-53(Fe)@Ori demonstrated a pH-responsive release processes.

At $\mathrm{pH} 7.2,82.23 \%$ of Ori was released over $168 \mathrm{~h}$. When the $\mathrm{pH}$ value was reduced to $5.5,91.75 \%$ of Ori was released in $168 \mathrm{~h}$ (Figure 4b). The characteristic release parameters were explored by different mathematical models to explain the mechanism of drug release, and the fitting results are shown in Figure 5. At pH 5.5, the release profile of Ori@MIL-53(Fe) followed the Weilbull distribution with a regression factor of $>0.987$ (Figure 5a). Whereas at $\mathrm{pH} 7.2$, the release profile of Ori@MIL-53(Fe) followed fist-order kinetics $(\ln (1-$ Ori $)=k t+b)$ with regression factor of $>0.995$ (Figure $6 b$ ). 
(a)

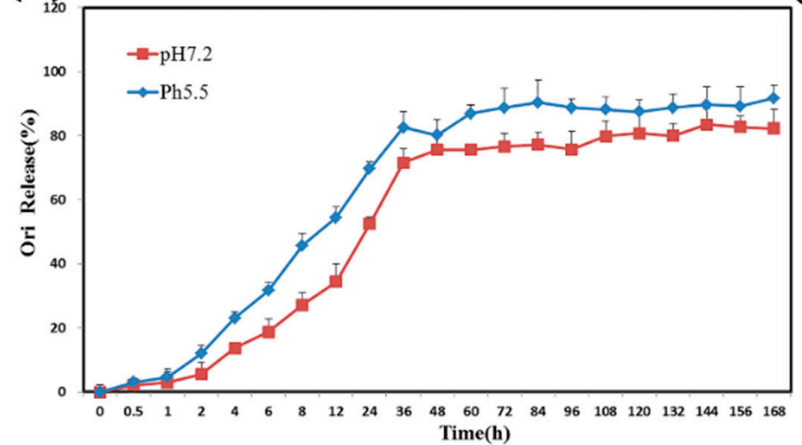

(b)

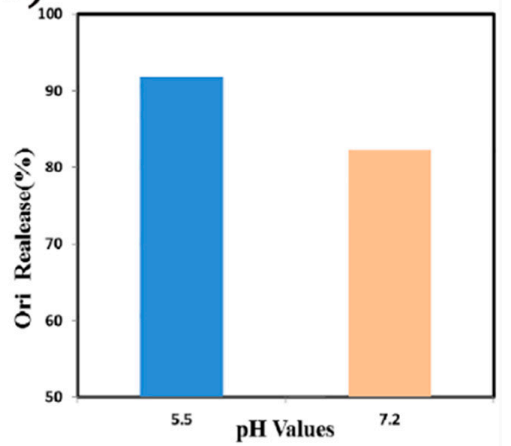

Figure 5. (a) The release curve of Ori@MIL-53(Fe) under different $\mathrm{pH}$ values. (b) The total release of Ori.

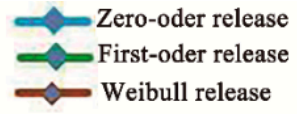

(a)
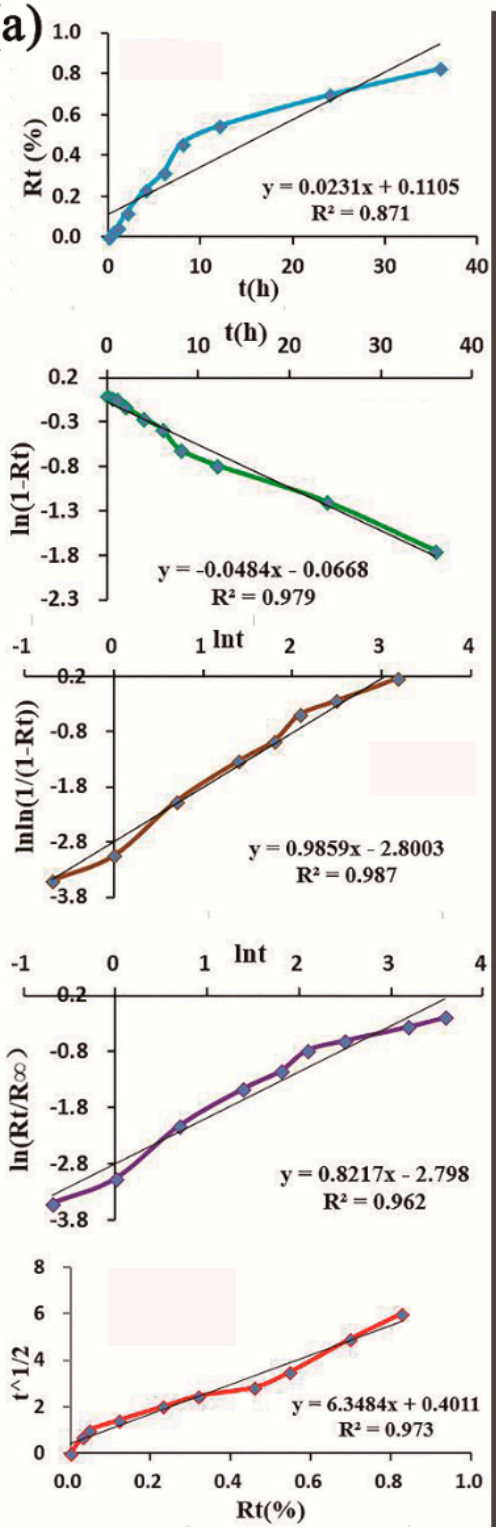

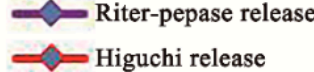

$\begin{array}{lll}\text { (a) } \mathrm{pH} 5.5 & \text { (b) } \mathrm{pH} 7.2\end{array}$
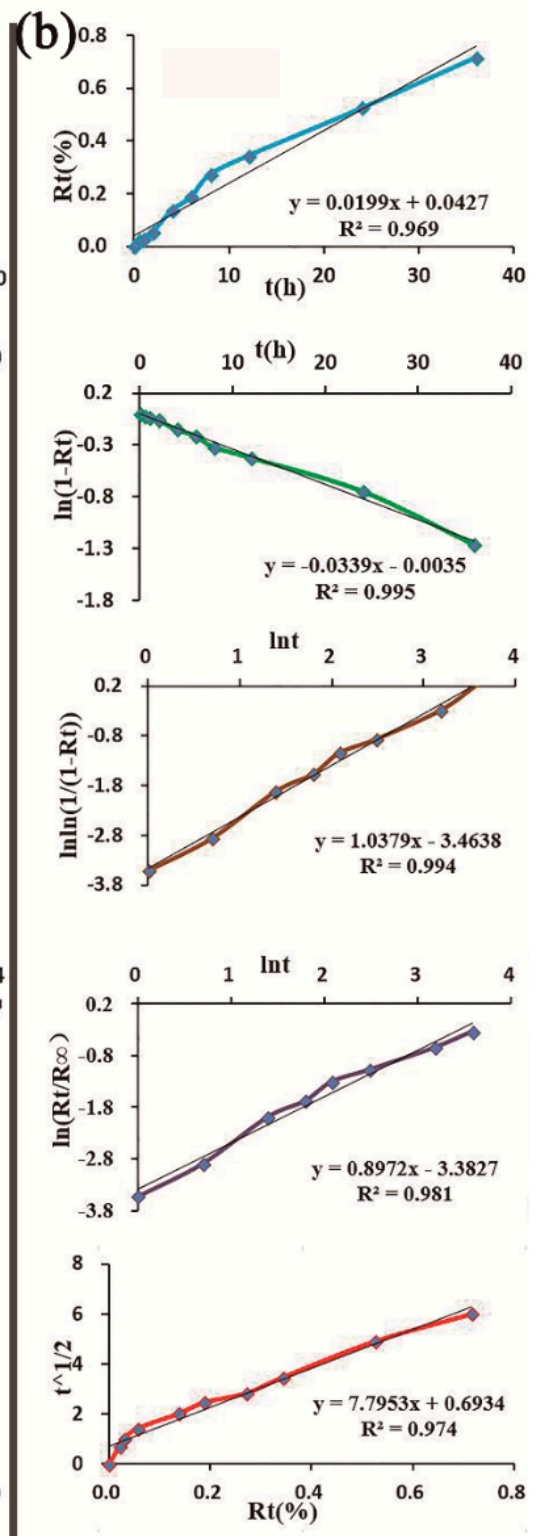

Figure 6. Fitting curve by different mathematical models under different $\mathrm{pH}$ values: (a) $\mathrm{pH}=5.5$ and (b) $\mathrm{pH}=7.2, \mathrm{Rt}=$ accumulated release rat. 


\subsection{Safety Evaluation of MIL-53(Fe)}

The results of 3-[4,5-dimethylthiazol-2-yl]-2,5 diphenyltetrazolium bromide (MTT) assays are shown in Figure 7a. There was no significant difference in the viability of HepG2 cells when MIL-53(Fe) with different concentrations were compared with vehicle controls $(p>0.05)$. In addition, the experimental results showed that MIL-53(Fe) treatment did not increase lactate dehydrogenase (LDH) release, as shown in Figure $7 \mathrm{~b}$.

The percentage of viable cells, early apoptotic cells, and late apoptotic cells did not obviously change, after HepG2 cells were treated with MIL-53(Fe) for $24 \mathrm{~h}$ (Figure 8). The MIL-53(Fe) did not result in cells' morphological changes and good biocompatibility of MIL-53(Fe) with HepG2 cells was observed.
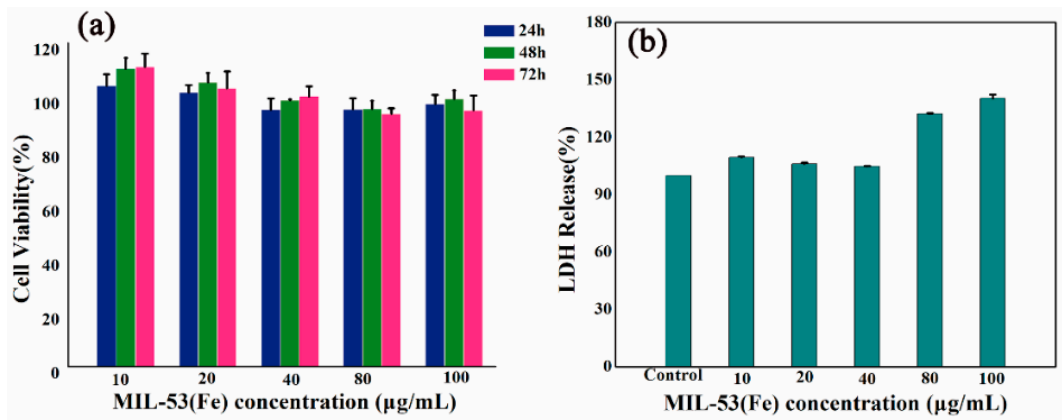

Figure 7. Effects of MIL-53(Fe) on cell viability and morphology. (a) MTT assay data were presented as mean \pm SD of viability \% of three independent experiments. (b) Evaluate HepG2 cells nuclear morphology by DAPI staining.
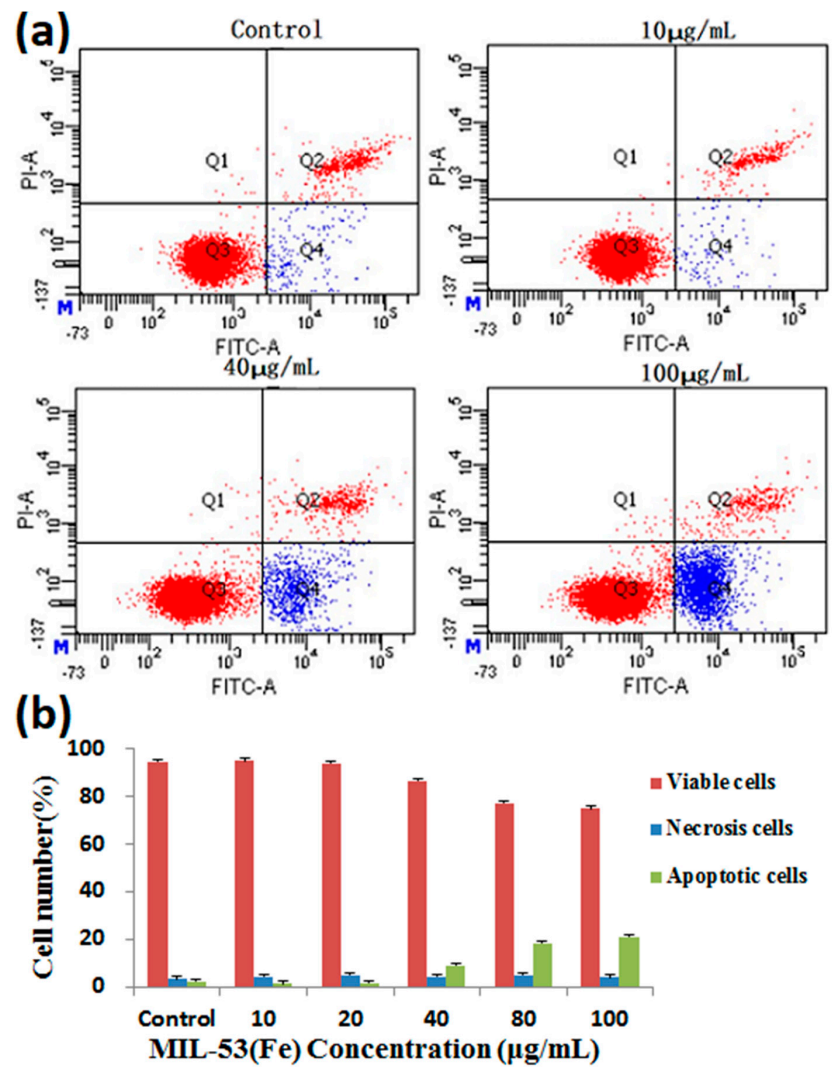

Figure 8. Effects of MIL-53(Fe) on apoptosis in HepG2 cells. (a) Flow cytometry detection of apoptosis with FITC-Annexin V/PI double staining. (b) The percentages of viable, early apoptosis and late apoptosis of HepG2 cells after incubation with different concentrations of MIL-53(Fe) for $24 \mathrm{~h}$. The data are expressed as means \pm S.D. from three independent experiments. 


\subsection{Cytotoxic Effect of Ori@MIL-53(Fe) on HepG2 Cells}

HepG2 cells were incubated with free Ori $(0,10,15,20,25$, and $30 \mu \mathrm{g} / \mathrm{mL})$ for 24,48 , and $72 \mathrm{~h}$. As shown in Figure 9a, the treatment of HepG2 cells with Ori resulted in a significant inhibition of cell viability in both a dose- and time-dependent manner. We calculated the concentration of Ori $(0,10,15$, $20,25$, and $30 \mu \mathrm{g} / \mathrm{mL})$ in Ori@MIL-53(Fe) $(0,19,28,38,48$, and $57 \mu \mathrm{g} / \mathrm{mL})$ required to incubate HepG2 cells (Figure 9b). Ori@MIL-53(Fe) induced HepG2 cell death in a dose- and time- dependent manner, but within $48 \mathrm{~h}$ could not attain the same effect as free Ori in the same concentrations. This shows that Ori in Ori@MIL-53(Fe) was slowly released. However, the inhibition of Ori@MIL-53 (Fe) after 72 h reached the same level of the free drug, as shown in Figure 9c.
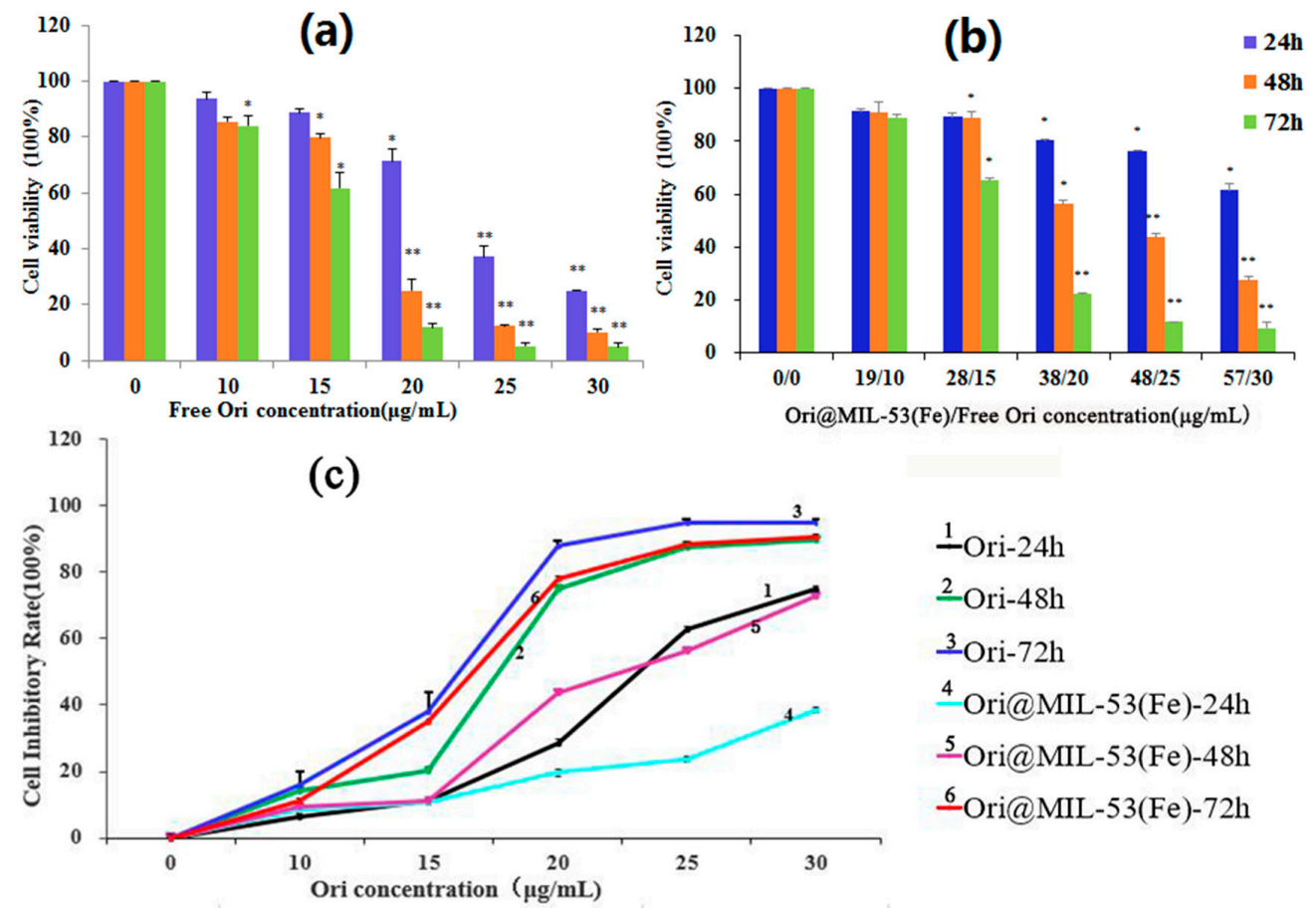

1 Ori-24h

$\underline{2}$ Ori-48h

- $O$ ri-72h

$\stackrel{4}{-}$ Ori@MIL-53(Fe)-24h

- Ori@MIL-53(Fe)-48h

- $\mathrm{Ori} @ M I L-53(\mathrm{Fe})-72 \mathrm{~h}$

Figure 9. Effects of (a) Ori and (b) Ori@MIL-53(Fe) on cell viability. (c) HepG2 cell proliferation inhibiting rate.MTT assay date were presented as mean \pm SD of viability $\%$ of three independent experiments. $\left({ }^{*} p<0.05\right.$ vs. Control, ${ }^{* *} p<0.01$ vs. Control).

\section{Discussion and Conclusions}

MOFs have a wide range of compositions, crystalline structures, and crystal shapes, providing advantages over other types of materials [34]. Since the late 1990s, MOFs have been widely used in gas adsorption and separation [35] supercapacitor electrodes, catalysis, sensing [36], bio-imaging, and magnetism [37]. Some MOFs have extra-large surface areas, high-connectivity polyhedral cages, large pore volumes, high stability, nontoxicity, biocompatibility, and small sizes, making them potential excellent nanocarriers in the biomedical field [38]. These nanomedical materials can be used for various purposes, such as imaging agents for early and minimally invasive diagnosis, for specific cell and tissue (more commonly used in tumor tissue) targeting, entrapping high loadings of a drug, increased drug concentration in a local site, and creating drug-delivery formulations [39-41]. For example, Gordon, using an incipient wetness impregnation method, successfully loaded three model drugs (acetaminophen, progesterone, and stavudine) into MIL-53(Fe), MIL-101, and SBA-15 (20 wt \%). the MIL-53(Fe) framework was slowly released for up to six days for acetaminophen in a diffusion-controlled process [31]. Motakef-Kazemi prolonged the release of ibuprofen for up to three weeks using $\mathrm{Zn}_{2}(\mathrm{BDC})_{2}(\mathrm{DABCO})$ for loading ibuprofen (30 wt \%) [42]. In the present work, we synthesized a carrier material named MIL-53(Fe), which has been proven to 
be biocompatible, and encapsulated the anticancer drug Ori. We successfully built a drug delivery system, Ori@MIL-53(Fe), in which MIL-53(Fe) acted as the drug vehicle. This system had an efficient drug-loading capacity of $56.25 \mathrm{wt} \%$, which was higher than previously reported. The reason for the increase in efficiency is that we used orthogonal design $\mathrm{L}_{9}\left(4^{3}\right)$ to optimize the drug loading process and analyze different factors affecting drug loading. This drug loading method enables MIL-53(Fe) to be used to package other drugs.

The wide range of applications of MOFs have produced many debates among the scientific community about whether MOFs are biologically friendly in biomedical applications. Currently, the toxicity evaluation of MOFs has mostly been restricted metals and linkers individually. The literature and early results have shown that the toxicity of $\mathrm{Mg}, \mathrm{Fe}, \mathrm{Zn}$, and $\mathrm{Zr}$, as evaluated by their $\mathrm{LD}_{50}$, varied from a few $\mu \mathrm{g} / \mathrm{kg}$ up to more than $1 \mathrm{~g} / \mathrm{kg}$ due to the different chemical formulations [43]. The organic linkers, such as polycarboxylic or imidazolate, are not very toxic due to their high polarity and a priori easy removal under physiological conditions [44]. The flexibility with which metal clusters and organic linkers can be varied, the ability to change the physical and chemical properties of solids, and their functionalization inside and outside the surface are additional advantages of MOFs [45]. The range of cytotoxicity, host-guest interactions, hydrophobic/hydrophilic balance, biodegradability, body distribution, tissue accumulation, and excretabilty are beneficial aspects of their safety and determine whether they can be used in biological application. Before practical application of any novel MOFs, especially in a medical context, comprehensive studies of its cellular biocompatibility and nanosafety are required. In vitro toxicity tests, which are rapid, effective, inexpensive, and provide information of possible cell and nanoparticle interactions, are used to assess potential hazards of nanomaterials [46]. In this study, we used MTT assays, LDH assays, and Annexin V-FITC/PI double-staining assays to study the cell safety of MIL-53(Fe) on HepG2 cells. These assays are suitable for high-throughput screening of most new medical nanomaterials as they can establish a cytotoxicity ranking. Therefore, studying the possible toxic effects of MOFs is important.

Various new DDS can be designed according to clinical need, such as for high load capacity of different passenger molecules, tumor targeted therapy, drug release, and according to other external stimulus factors, such as $\mathrm{pH}$ value, temperature, light irradiation, and redox reagents $[43,44,47]$. From our study, we found that the release rate at $\mathrm{pH} 5.5$ was faster than that at $\mathrm{pH} 7.2$, which was presumed to be due to the effect of acidic environments on the conversion between the large and small hole of MIL-53(Fe), which may confirm $\mathrm{pH}$-sensitive release. The portion of the drug load that was successfully incorporated within the MIL-53(Fe) framework was slowly released over as long as seven days for Ori in a diffusion-controlled process. Therefore, MIL-53(Fe) can change the pharmacokinetics of Ori, prolong circulation time, significantly enhance the antitumor effect, minimize the dosage, and reduce toxic side-effects of drugs.

In conclusion, this study reports for the first time that flexible porous MIL-53(Fe) could be used as a vector for the traditional medicine monomer Ori, with drug release at $\mathrm{pH} 5.5$ showing a Weilbull distribution, and first-order kinetics drug release at $\mathrm{pH}$ 7.2. More than $82 \%$ of Ori in Mil-53(Fe) was released at $\mathrm{pH}$ values of 5.5 and 7.2. The release experiment showed that the release rate was faster in low $\mathrm{pH}$ environments than in higher $\mathrm{pH}$ environments. The MIL-53( $\mathrm{Fe})$ offers many possibilities to achieve the adequately controlled release of various pharmacological molecules. Ori@MIL-53(Fe) inhibited the growth of HepaG2 cells at $28-57 \mu \mathrm{g} / \mathrm{mL}$ (equivalent to $15-30 \mu \mathrm{g} / \mathrm{mL}$ of free Ori). The suppression was both time- and dose-dependent. However, the toxicity of Ori@MIL-53(Fe) was lower than that of free Ori in equal drug concentrations, which was caused by the slow release of Ori@MIL-53(Fe). The Ori loading in MIL-53(Fe) samples proves the potential of these systems for drug delivery applications. We expect that the success of the present findings will not only provide a new approach for Ori delivery, but also pave the way for the development of new porous MOFs for practical bio-applications. 


\section{Methods}

\subsection{Synthesis and Characterization of MIL-53(Fe)}

The MIL-53(Fe) was synthesized by a previously reported solvent thermal method [37]. In a typical experiment, a mixture of $\mathrm{FeCl}_{3}$, terephthalic acid (BDC) and $N, N$-dimethylformamide (DMF) with a molar ratio of 1:1:280 was mixed and sonicated for a $10 \mathrm{~min}$, then placed in a Teflon lined steel autoclave, heating at $150{ }^{\circ} \mathrm{C}$ for $15 \mathrm{~h}$ and cooling to the temperature. Light brown powder was obtained by centrifuging using DMF as solvent and then stirring in methanol for three days. Finally, the solid powder was heated at $150{ }^{\circ} \mathrm{C}$ overnight to remove guest molecules $\left(\mathrm{H}_{2} \mathrm{O}, \mathrm{DMF}\right.$, and methanol). Synthesized MIL-53(Fe) was characterized by SEM and PXRD analysis. PXRD with Cu-K $\alpha$ irradiation from $5^{\circ}$ to $50^{\circ}(2 \theta)$ were used to evaluate the size, purity and crystallinity of synthesized MIL-53(Fe).

\subsection{Stability of MIL-53(Fe) in FBS}

MIL-53(Fe) was dissolved in methanol to obtain a $5 \mathrm{mg} / \mathrm{L}$ solution. FBS was diluted with PBS before testing. A $0.2 \mathrm{~mL}$ portion of the diluted solution of MIL-53(Fe) was added to $4.8 \mathrm{~mL}$ of FBS (pre-warmed to $37^{\circ} \mathrm{C}$ for $30 \mathrm{~min}$ prior to experiments). After being incubated at $37^{\circ} \mathrm{C}$ for $0,1,2,4,8$, $12,24,48$ and $72 \mathrm{~h}$, observe if there is a deposit at the bottom. Zeta potential was tested with a Zetasizer (ZEN3690, Malvern Instruments Ltd., Malvern, UK).

\subsection{Encapsulation and Evaluation of Ori@MIL-53(Fe)}

The encapsulation of drugs was performed by a solvent diffusion technique. MIL-53(Fe) was added into a vial with different concentrations of Ori methanol solution, and after that, stirred for 2, 3 or 4 days at room temperature. The drug-loaded MIL-53(Fe) were then collected by centrifugation and washed with methanol three times. The concentration of Ori was determined by high performance liquid chromatography (HPLC, methanol:water $=55: 45, \lambda=295 \mathrm{~nm}$ ) based on a one point external standard method. Because the Ori@MIL-53(Fe) is methanol-insoluble, the percentage of adsorbed mass of oridonin was determined by subtracting the amount of final mass from its initial mass incorporated for use, and loading capacity (LC) formula is as follows:

$$
\mathrm{LC} \%=\frac{M_{0}-M_{e}}{M} \times 100 \%
$$

where $M_{0}$ and $M_{e}$ are the initial amount and final amount of Ori (mg) in the system, respectively. $M$ denotes the amount of Ori@MIL-53(Fe) (mg).

In addition, in order to study the physical state of the Oridonin in the porous framework, SEM, TEM, XPRD, DSC heating from $40{ }^{\circ} \mathrm{C}$ to $300{ }^{\circ} \mathrm{C}$ with a heating rate of $10.00{ }^{\circ} \mathrm{C} / \mathrm{min}$ and FTIR were performed.

\subsection{In Vitro Release Studies}

The release of the drug oridonin from Ori@MIL-53(Fe) was estimated in PBS solution at two different $\mathrm{pH}$ values ( $\mathrm{pH} 7.2$ and $\mathrm{pH} 5.5)$ at $37{ }^{\circ} \mathrm{C}$. Approximately $10 \mathrm{mg}$ of Ori@MIL-53(Fe) powder wase placed in a dialysis bag (MD $34 \mathrm{~mm})$ and soaked in PBS $(100 \mathrm{~mL})$. The drug release experiment was performed under sink conditions. At different time intervals, digestion liquor $(100 \mu \mathrm{L})$ was extracted and filtered through a $0.45 \mu \mathrm{m}$ polytetrafluoroethylene membrane filter. The released amount of Ori was measured by HPLC using an Agilent Zorbax SB-C18 column. Concentrations were calculated by interpolation from the calibration curves using linear regression models. The oridonin calibration curves were linear over the concentration range of $0.06 \mu \mathrm{g} / \mathrm{mL}$ to $84.00 \mu \mathrm{g} / \mathrm{mL}\left(\mathrm{y}=26292 \mathrm{x}-8127, \mathrm{r}^{2}=0.999\right)$. The concentration was used to calculate the cumulative drug release after each time interval. 


\subsection{Cell Culture}

The HepG2 cells from the hepatoma cells of human (Jenniobio Biotechnoliyg, Guangzhou, China) were cultured with the samples of the solution to evaluate the cytotoxicity. They were cultured with Dulbecco's Modified Eagle Medium (DMEM) supplemented with 10\% FBS and 1\% penicillin-streptomycin solution, followed by incubation in a humidified atmosphere of $5 \% \mathrm{CO}_{2}$ at $37^{\circ} \mathrm{C}$. The culture medium was refreshed every 2 or 3 days.

\subsection{Cytotoxicity Assay}

The cytotoxicity of Ori@MIL-53(Fe) was evaluated by a MTT assay of cellular viability on the hepatocellular carcinoma HepG2 cells from human. HepG2 cells were seeded in 96-well plates at a density of $3 \times 10^{3}$ cells per well. After the cell attached to the wall, the solutions with different concentrations of MIL-53(Fe), Ori@MIL-53(Fe) and free Ori were added into the well and continued to be cultured for $24 \mathrm{~h}, 48 \mathrm{~h}$ and $72 \mathrm{~h}$. After the prescribed time, the MTT solution with a concentration of $5 \mathrm{mg} / \mathrm{mL}$ was added to each well and incubated for $4 \mathrm{~h}$ at $37^{\circ} \mathrm{C}$. Culture supernatant was removed from all the wells, dimethyl sulfoxide (DMSO, $150 \mu \mathrm{L}$ ) was added to each well, and the plate was shaken for $10 \mathrm{~min}$. Absorbance of the formazan solution was read at $570 \mathrm{~nm}$ in a microplate reader. The results were expressed as the percentage of cell viability. All tests were repeated three times.

\subsection{LDH Assay}

Lactate dehydrogenase (LDH), which is present mainly in the cytoplasm and exists in the extracellular medium, is used to investigate cell membrane integrity damage. LDH leakage is considered as a sign of cell membrane disruption [48]. For the measurement of LDH, HepG2 cells were seeded into 96-well plates overnight and then treated with various concentrations of MIL-53(Fe) for $48 \mathrm{~h}$. After $48 \mathrm{~h}$ treatment, the supernatant was collected to determined LDH activity with a commercial kit. All of the experimental tests were performed three times.

\subsection{Annexin V/PI Double-Staining Assay}

Apoptotic cells were quantified using an Annexin V-FITC detection kit and analyzed by flow cytometry. In this process, HepG2 cells were seeded in 6-well plates at a density of $3.5 \times 10^{5}$ cells/well and treated with different concentrations of MIL-53(Fe) for $24 \mathrm{~h}$ at $37^{\circ} \mathrm{C}$. The cells were washed with PBS and resuspended in $295 \mu \mathrm{L}$ binding buffer. Annexin V-FITC $(5 \mu \mathrm{L})$ and PI $(10 \mu \mathrm{L})$ were added, and the mixture was incubated for $20 \mathrm{~min}$ at $37^{\circ} \mathrm{C}$ in the dark. Finally, apoptotic cells were immediately analyzed by flow cytometry.

Author Contributions: X.L., X.Y., and J.N. designed the research. X.L., X.D., L.Y., W.W. and C.Y. performed the experiments. H.H. and N.S. conducted the data analyses. X.L. wrote the paper. All authors reviewed the manuscript.

Funding: This work was financially supported by the National Natural Science Foundation of China (No. 81703715, 21536001 and 21606007), the Training Programme Foundation for the Beijing Municipal Excellent Talents (No. 2017000020124G295) and the fundamental Research Funds for the Central Universities (Beijing University of Chinese Medicine Scientific Research Project for Distinguished Young Scholar (No. 2018-JYB-XJQ005).

Conflicts of Interest: The authors declare no conflict of interest.

\section{References}

1. Zhang, X.Q.; Zhang, H.M.; Sun, X.E. Inhibitory effects and mechanism of 5-fluorouracil combined with celecoxib on human gastric cancer xenografts in nude mice. Exp. Ther. Med. 2015, 9, 105-111. [CrossRef] [PubMed]

2. Tian, L.; Xie, K.; Sheng, D.; Wan, X.; Zhu, G. Antiangiogenic effects of oridonin. BMC Complem. Altern. Med. 2017, 17, 192. [CrossRef] [PubMed] 
3. Qi, Q.; Zhang, P.; Li, Q.X.; Pan, Q.; Zheng, H.L.; Zhao, S.R. Effect of Oridonin on apoptosis and intracellular reactive oxygen species level in triple-negative breast cancer MDA-MB-231 cells. Zhongguo Zhong Yao Za Zhi. 2017, 42, 2361-2365. [PubMed]

4. Xia, S.X.; Zhang, X.L.; Li, C.H.; Guan, H.L. Oridonin inhibits breast cancer growth and metastasis through blocking the Notch signaling. Saudi Pharm. J. 2017, 25, 638-643. [CrossRef] [PubMed]

5. Wang, X.H.; Zhang, S.F.; Bao, J.T.; Liu, F.Y. Oridonin synergizes with Nutlin-3 in osteosarcoma cells by modulating the levels of multiple Bcl-2 family proteins. Tumour Biol. 2017, 39, 6. [CrossRef] [PubMed]

6. Xu, T.; Jin, F.; Wu, K.R.; Ye, Z.P.; Li, N. Oridonin enhances in vitro anticancer effects of lentinan in SMMC-7721 human hepatoma cells through apoptotic genes. Exp. Ther. Med. 2017, 14, 5129-5134. [CrossRef] [PubMed]

7. Lu, J.; Chen, X.; Qu, S.; Yao, B.; Xu, Y.; Wu, J.; Jin, Y.; Ma, C. Oridonin induces G2/M cell cycle arrest and apoptosis via the PI3K/Akt signaling pathway in hormone-independent prostate cancer cells. Oncol. Lett. 2017, 13, 2838-2846. [CrossRef] [PubMed]

8. Zhao, J.; Zhang, M.; He, P.; Zhao, J.; Chen, Y.; Qi, J.; Wang, Y. Proteomic analysis of oridonin-induced apoptosis in multiple myeloma cells. Mol. Med. Rep. 2017, 15, 1807-1815. [CrossRef] [PubMed]

9. Wang, H.; Ye, Y.; Chui, J.H.; Zhu, G.Y.; Li, Y.W.; Fong, D.W.; Yu, Z.L. Oridonin induces G2/M cell cycle arrest and apoptosis through MAPK and p53 signaling pathways in HepG2 cells. Oncol. Rep. 2010, 24, 647-651. [PubMed]

10. Wang, H.; Ye, Y.; Yu, Z.L. Proteomic and functional analyses demonstrate the involvement of oxidative stress in the anticancer activities of oridonin in HepG2 cells. Oncol. Rep. 2014, 31, 2165-2172. [CrossRef] [PubMed]

11. Wang, Y.; Liu, X.Q.; Liu, G.P.; Guo, H.J.; Li, C.Y.; Zhang, Y.C.; Zhang, F.; Zhao, Z.X.; Cheng, H.L. Novel galactosylated biodegradable nanoparticles for hepatocyte-delivery of oridonin. Int. J. Pharm. 2016, 502, 47-60. [CrossRef] [PubMed]

12. Wang, C.; Li, W.; Hu, B. The Anti-tumor Effect of Folate-targeted Liposome Microbubbles Loaded with Oridonin as Ultrasound-triggered Tumor-targeted Therapeutic Carrier System. J. Drug Target. 2017, 25, 83-91. [CrossRef] [PubMed]

13. Sun, K.Q.; Guo, J.H.; He, Y.F.; Song, P.F.; Xiong, Y.B.; Wang, R.M. Fabrication of dual-sensitive keratin-based polymer hydrogels and their controllable release behaviors. J. Biomater. Sci. Polym. Ed. 2016, 27, 1926-1940. [CrossRef] [PubMed]

14. Oliveri, V.; Bellia, F.; Viale, M.; Maric, I.; Vecchio, G. Linear polymers of $\beta$ and $\gamma$ cyclodextrins with a polyglutamic acid backbone as carriers for doxorubicin. Carbohyd. Polym. 2017, 177, 355-360. [CrossRef] [PubMed]

15. De Moraes Nogueira, A.O.; de Sousa, R.S.; Pereira, L.S.; Mallmann, C.; da Silva Ferreira, A.; Clementin, R.M.; de Lima, V.R. Physicochemical interactions among $\alpha$-eleostearic acid-loaded liposomes applied to the development of drug delivery systems. J. Mol. Struct. 2018, 1154, 248-255. [CrossRef]

16. Chen, Q.; Zheng, J.W.; Yuan, X.Z.; Wang, J.F.; Zhang, L.J. Folic acid grafted and tertiary amino based $\mathrm{pH}$-responsive pentablock polymeric micelles for targeting anticancer drug delivery. Mater. Sci. Eng. R 2018, 82, 1-9. [CrossRef] [PubMed]

17. Su, C.M.; Huang, C.Y.; Chen, Y.L.; Ger, T.R. pH-responsive magnetic micelles gelatin-g-poly (NIPAAm-coDMAAm-co-UA)-g-dextran/Fe3O4 as a hydrophilic drug carrier. RSC Adv. 2018, 7, 28207-28212. [CrossRef]

18. Tian, Z.F.; Yu, X.; Ruan, Z.J.; Zhu, M.; Zhu, Y.F.; Hanagata, N. Magnetic mesoporous silica nanoparticles coated with thermo-responsive copolymer for potential chemo- and magnetic hyperthermia therapy. Microporous Microporous Mater. 2018, 256, 1-9. [CrossRef]

19. Tran, V.A.; Lee, S.W. A prominent anchoring effect on the kinetic control of drug release from mesoporous silica nanoparticles (MSNs). J. Colloid Interface Sci. 2018, 510, 345-356. [CrossRef] [PubMed]

20. Duo, Y.H.; Li, Y.; Chen, C.K.; Liu, B.Y.; Wang, X.Y.; Zeng, X.W.; Chen, H.B. DOX-loaded pH-sensitive mesoporous silica nanoparticles coated with PDA and PEG induce pro-death autophagy in breast cancer. RSC. Adv. 2017, 7, 39641-39650. [CrossRef]

21. Qin, Y.; Wang, C.Y.; Jiang, Y.; Liu, T.; Yang, J.Y.; Lin, R.; Zhang, T. Phosphorylcholine oligomer-grafted graphene oxide for tumor-targeting doxorubicin delivery. RSC. Adv. 2017, 7, 41675-41685. [CrossRef]

22. Yan, L.; Chen, X.F.; Wang, Z.G.; Zhang, X.J.; Zhu, X.Y.; Zhou, M.J.; Chen, W.; Huang, L.B.; Roy, V.A.L.; Yu, P.K.N.; et al. Size Controllable and Surface Tunable Zeolitic Imidazolate Framework-8-Poly (acrylic acid sodium salt) Nanocomposites for $\mathrm{pH}$ Responsive Drug Release and Enhanced in Vivo Cancer Treatment. ACS Appl. Mater. Interface 2017, 9, 32990-33000. [CrossRef] [PubMed] 
23. Bugnicourt, L.; Ladaviere, C. A close collaboration of chitosan with lipid colloidal carriers for drug delivery applications. J. Control. Release 2017, 256, 121-140. [CrossRef] [PubMed]

24. Baeza, A.; Ruiz-Molina, D.; Vallet-Regí, M. Recent advances in porous nanoparticles for drug delivery in antitumoral applications: Inorganic nanoparticles and nanoscale metal-organic frameworks. Expert Opin. Drug Deliv. 2017, 14, 783-796. [CrossRef] [PubMed]

25. Orellana-Tavra, C.; Baxter, E.F.; Tian, T.; Bennett, T.D.; Slater, N.K.; Cheetham, A.K.; Fairen-Jimenez, D. Amorphous metal-organic frameworks for drug delivery. Chem. Commun. 2015, 51, 13878-13881. [CrossRef] [PubMed]

26. Jiang, K.; Zhang, L.; Hu, Q.; Zhang, Q.; Lin, W.X.; Cui, Y.J.; Yang, Y.; Qian, G.D. Thermal Stimuli-Triggered Drug Release from a Biocompatible Porous Metal-Organic Framework. Chem. Eur. J. 2017, 23, 10215-10221. [CrossRef] [PubMed]

27. Wei, L.Q.; Li, Y.; Mao, L.Y.; Chen, Q.; Lin, N. A series of porous metal-organic frameworks with hendecahedron cage: Structural variation and drug slow release properties. J. Solid State Chem. 2018, 257, 58-63. [CrossRef]

28. Wang, J.; Ma, D.Y.; Liao, W.L.; Li, S.J.; Huang, M.F.; Liu, H.M.; Wang, Y.F.; Xie, R.; Xu, J. A hydrostable anionic zinc-organic framework carrier with a bcu topology for drug delivery. Crystengcomm 2017, 19, 5244-5250. [CrossRef]

29. Lin, S.; Liu, X.M.; Tan, L.; Cui, Z.D.; Yang, X.J.; Yeung, K.W.K.; Pan, H.B.; Wu, S.L. Porous Iron-Carboxylate Metal-Organic Framework: A Novel Bioplatform with Sustained Antibacterial Efficacy and Nontoxicity. ACS Appl. Mater. Interfaces 2017, 9, 19248-19257. [CrossRef] [PubMed]

30. Pereacachero, A.; Romero, E.; Ariso, C.T. Insight into the reversible structural crystalline-state transformation from MIL-53(Al) to MIL-68(Al). Crystengcomm 2018, 20, 402-406. [CrossRef]

31. Gordon, J.; Kazemian, H.; Rohani, S. MIL-53(Fe), MIL-101, and SBA-15 porous materials: Potential platforms for drug delivery. Mater. Sci. Eng. C Mater. 2015, 47, 172-179. [CrossRef] [PubMed]

32. Férey, G.; Serre, C. Large breathing effects in three-dimensional porous hybrid matter: Facts, analyses, rules and consequences. Chem. Soc. Rev. 2009, 38, 1380-1399. [CrossRef] [PubMed]

33. Horcajada, P.; Serre, C.; Guillaume, M.; Naseem, R.; Maria, V.R.; Sebban, M.; Francis, T.; Gerard, F. Flexible Porous Metal-Organic-Frameworks for a controlled drug delivery. J. Am. Chem. Soc. 2008, 435, 6774-6780. [CrossRef] [PubMed]

34. Tamames, T.C.; García-Márquez, A.; Blanco-Prieto, M.J. MOFs in pharmaceutical technology. Bio-Bioinspired Nanomater. 2014, 83-112. [CrossRef]

35. Alkordi, M.H.; Belmabkhout, Y.; Cairns, A.; Eddaoudi, M. Metal-organic frameworks for $\mathrm{H}_{2}$ and $\mathrm{CH}_{4}$ storage: Insights on the pore geometry-sorption energetics relationship. IUCrJ 2017, 4, 131-135. [CrossRef] [PubMed]

36. Wang, Z.; Chen, Q. Vapochromic behavior of MOF for selective sensing of ethanol. Spectrochim. Acta A 2017, 184, 158-162. [CrossRef] [PubMed]

37. Mínguez, E.G.; Coronado, E. Magnetic functionalities in MOFs: From the framework to the pore. Chem. Soc. Rev. 2018, 47, 533-557. [CrossRef] [PubMed]

38. Ibrahim, M.; Sabouni, R.; Husseini, G.A. Anti-cancer drug delivery using metal organic frameworks (MOFs). Curr. Med. Chem. 2017, 24, 193-214. [CrossRef] [PubMed]

39. Hao, J.N.; Xu, X.Y.; Lian, X.; Zhang, C.; Yan, B. A Luminescent 3d-4f-4d MOF Nanoprobe as a Diagnosis Platform for Human Occupational Exposure to Vinyl Chloride Carcinogen. Inorg. Chem. 2017, 56, 11176-11183. [CrossRef] [PubMed]

40. Zhang, H.; Jiang, W.; Liu, R.; Zhang, J.; Zhang, D.; Li, Z. Rational Design of Metal Organic Framework Nanocarrier-Based Codelivery System of Doxorubicin Hydrochloride/Verapamil Hydrochloride for Overcoming Multidrug Resistance with Efficient Targeted Cancer Therapy. ACS Appl. Mater. Interfaces 2017, 9, 19687-19697. [CrossRef] [PubMed]

41. Ananthoji, R.; Eubank, J.F.; Nouar, F.; Mouttaki, H. Symbiosis of zeolite-like metal-organic frameworks (rho-ZMOF) and hydrogels: Composites for controlled drug release. J. Mater. Chem. 2011, 21, 587-9594. [CrossRef]

42. Motakef, K.N.; Shojaosadati, S.A.; Morsali, A. Evaluation of the effect of nanoporous nanorods Zn 2 (bdc) 2 (dabco) dimension on ibuprofen loading and release. J. Iranian Chem. Soc. 2016, 13, 1205-1212. [CrossRef] 
43. Horcajada, P.; Gref, R.; Baati, T. Metal-organic frameworks in biomedicine. Chem. Rev. 2012, 112, $1232-1268$. [CrossRef] [PubMed]

44. Shen, L.; Helan, X.; Yang, Y. Quantitative correlation between cross-linking degrees and mechanical properties of protein films modified with polycarboxylic acids. Macromol. Mater. Eng. 2015, 300, 1133-1140. [CrossRef]

45. Furukawa, S.; Reboul, J.; Diring, S.; Sumida, K.; Kitagawa, S. Structuring of metal-organic frameworks at the mesoscopic/macroscopic scale. Chem. Soc. Rev. 2014, 43, 5700-5734. [CrossRef] [PubMed]

46. Sumit, A.; Jyutika, M.R.; Kishore, M.P. Nanotoxicology and in vitro studies: The need of the hour. Toxicol. Appl. Pharmacol. 2012, 258, 151-165.

47. Cao, Y.; Yang, J. Development of a Folate Receptor (FR)-Targeted Indenoisoquinoline Using a pH-Sensitive N-Ethoxybenzylimidazole (NEBI) Bifunctional Cross-Linker. Bioconjugate Chem. 2014, 25, 873-878. [CrossRef] [PubMed]

48. Dong, X.; Jing, F.; Yin, X. Induction of Apoptosis in HepaRG Cell Line by Aloe Emodin through Ceneration of Reactive Oxygen Species and the Mitochondrial Pathway. Cell. Physiol. Biochem. 2017, 42, 685-696. [CrossRef] [PubMed]

Sample Availability: Samples of the compounds are not available from the authors. 